\title{
Do pensamento social sobre a Amazônia
}

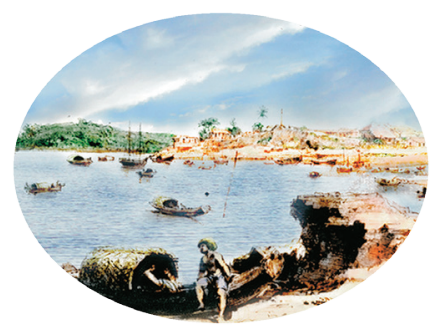

Gustavo Soranz*

\section{Resumo}

Buscamos apontar as ideias fundadoras dos discursos sobre a Amazônia nos relatos dos cronistas de viagens do século XVI, identificando como ela sintetiza os elementos do imaginário colonial europeu sobre o chamado Novo Mundo. Em seguida, destacamos o esforço empreendido por intelectuais em direção à desconstrução de estereótipos no sentido de valorizar o aspecto sociocultural da Amazônia.

Palavras-chave: Amazônia; novo mundo; exotismo.

\begin{abstract}
We seek to point out the ideas of the founding discourses on Amazon reports from travel writers of the sixteenth century, identifying how it synthesizes elements of European colonial imaginary about the so-called New World. Then highlight the efforts made by intellectuals toward the deconstruction of stereotypes in order to enhance the socio-cultural aspect of the Amazon.
\end{abstract}

Keywords: Amazon; new world; exotism.

\footnotetext{
*Bacharel em Comunicação Social. Mestre em Sociedade e Cultura na Amazônia (UFAM). Professor e coordenador do curso de Comunicação Social do Uninorte/Laureate International Universities. soranz@yahoo.com
} 


\section{Introdução}

As noções generalizadas sobre a região amazônica tendem a considerála sem história, sem permanência humana, imutável, sobre a qual predomina o conhecimento preconcebido, portanto, preconceituoso. Tais noções tendem a obscurecer o fato de que toda categoria existe dentro de um sistema de classificação, e que tal sistema é construído histórica e socialmente, portanto, é um sistema que está inserido em uma ordem hierárquica e que é impregnado de ideologia. Oliveira (2001, p. 104-105) diz que:

No nível da informação predomina o entendimento da Amazônia como exuberante, grandiosa, folclórica, fotogênica, concebendo apenas a paisagem natural, não considerando as relações sociais, concebendo o espaço como uma instância inumana (o homem é um intruso) sem captar o essencial no acidental, quase sempre separando as pessoas de seu espaço, como se fosse possível compreender o espaço sem as relações humanas. Neste sentido, a Amazônia é veiculada como espaço fragmentado em glebas, lotes, reservas, áreas de preservação, quase sempre superpondo territórios cujos limites não necessariamente coincidem com o espaço vivido.

Ver a territorialidade da Amazônia apenas do ponto de vista da natureza é inócuo, pois são as relações sociais que a constroem, a destroem, a inventam e a reconstroem num processo que pressupõe conflitos, contradições e lutas dos sujeitos.

Ao realizar um breve inventário das ideias preponderantes sobre a região, Oliveira (2001, p. 105) busca deslocar a questão das noções preconcebidas, dos determinismos, para a valorização do sujeito no processo de conhecimento da região, ressignificando o papel desse sujeito no seu processo histórico, destacando assim que esse é um processo de construção ideológica, que "pressupõe conflitos, contradições e lutas dos sujeitos".

Essa valorização do sujeito no processo de invenção da Amazônia, tal como esboçado por Oliveira em sua formulação, é um ponto central para uma 
revisão crítica da Amazônia enquanto uma categoria socialmente construída. Para essa revisão concretizar-se como empreendimento intelectual foi necessário aos autores que se propuseram a pensar o processo de formação do pensamento social sobre a Amazônia identificar ideias e autores que contribuiriam para o reconhecimento da gênese social das noções de Amazônia tal como os discursos predominantes ajudaram a difundir através da história do pensamento ocidental. Para Pinto (2006, p. 29)

A Amazônia e o próprio Brasil têm sido pensados e interpretados tendo como ponto de partida um núcleo perfeitamente identificável de ideias, noções, conceitos e preconceitos que constitui o fundamento dessas obras. É necessário descobrir e compreender como suas ideias surgem, se investem de significação e percorrem os espaços reais e imaginários da vida e da sociedade.

\section{Gênese social das concepções sobre a Amazônia}

Para estabelecer então qual é a origem dos discursos sobre a Amazônia, de onde são construídos, sob qual perspectiva e quais conceitos vão erigir sobre a região, alguns autores vão recuperar narrativas desde o século XVI, do período de reconhecimento do Brasil e do vale amazônico por parte do europeu colonizador e, a partir da matriz desse discurso vão analisar a construção da ideia de Amazônia, que se consolidaria mais tarde na modernidade e que permanece ainda nos dias de hoje nas narrativas acerca da região. Realizar esse percurso é, portanto, retomar a ideia de Novo Mundo que permeou as narrativas surgidas desde a descoberta das Américas, descoberta essa que "se deixa envolver pela aura do lendário, pela incerteza da paternidade do empreendimento; foi e continua sendo um veio rico para as especulações históricas, literárias, antropológicas, sociológicas etc.” (GONDIN, 1994, p. 13). Ao observarmos tais narrativas, podemos identificar "a Amazônia como um dos espaços mais característicos do Novo Mundo" (PINTO, 2006, p. 15).

As relações de poder colocadas no avanço da sociedade européia em suas conquistas do além-mar empreendidas nesse período são analisadas por 
Santos (2006, p. 181), que destaca uma relação desigual neste ato:

O acto da descoberta é necessariamente recíproco: quem descobre é também descoberto, e vice-versa. Porque é então tão fácil, em concreto, saber quem é descobridor e quem é descoberto? Porque sendo a descoberta uma relação de poder e de saber, é descobridor quem tem mais poder e mais saber e, com isso, a capacidade para declarar o outro como descoberto. É a desigualdade de poder e de saber que transforma a reciprocidade da descoberta na apropriação do descoberto.

Para Santos (2006, p. 181), além de serem descobertas fundamentadas numa relação de poder, o avanço marítimo das descobertas imperiais europeias da Idade Média também estava revestido de um forte elemento simbólico. Para o autor, as descobertas eram constituídas por duas dimensões: "uma empírica, o acto de descobrir, e outra, conceptual, a ideia do que se descobre.” Essa dimensão conceitual, ou simbólica como nos referimos, é fundamental para entender o desenvolvimento da representação da Amazônia nas narrativas da Idade Média e posteriormente na modernidade, sendo reiteradas ainda hoje nas diferentes representações contemporâneas sobre a Amazônia. Podemos dizer, assim, que a ideia de Amazônia foi, desde o início, um constructo social, uma ideia forjada a partir das narrativas dos viajantes que se aventuraram pelo chamado Novo Mundo e que se estende posteriormente pelos relatos científicos e artísticos sobre a região. Observar a gênese social do conceito de Amazônia pode auxiliar na compreensão dos modos de representação que se afirmaram sobre a região no desenrolar da história. Para Todorov (1999, p. 6)

não é unicamente por ser um encontro extremo, e exemplar, que a descoberta da América é essencial para nós, hoje. Além desse valor paradigmático, ela possui outro, de causalidade direta. A história do globo é, claro, feita de conquistas e derrotas, de colonizações e descobertas dos outros; mas, [...] é a conquista da América que anuncia e funda nossa identidade presente. 
Fundada sob a égide da colonização, a identidade brasileira ficou marcada pelos conflitos e contradições oriundas das relações problemáticas dos colonizadores e colonizados, marcadas por vários conflitos de interesse e troca desigual, que se objetivam em construções conceituais e categóricas que cristalizam verdades preconcebidas e classificações arbitrárias, que marcam a história do desenvolvimento social e cultural das colônias, assim como marcam a história das ideias e conceitos elaborados sobre essas regiões.

\section{As narrativas dos viajantes}

No contexto das grandes navegações do século XV, Cristovão Colombo foi um dos mais importantes navegadores que se lançaram ao projeto imperial das coroas europeias com intuito de dominar e explorar novas terras, distantes e desconhecidas. Ao analisar o empreendimento das conquistas européias do século XV, Todorov (1999, p. 20) argumenta que Colombo não tem nada de um empirista moderno: o argumento decisivo é o argumento de autoridade não o de experiência. Ele sabe de antemão o que vai encontrar; a experiência concreta está aí para ilustrar uma verdade que se possui, não para ser investigada, de acordo com regras preestabelecidas, em vista de uma procura da verdade. As narrativas decorrentes dos descobrimentos do além-mar empreendidos pelos europeus da Idade Média estavam impregnadas de imagens preconcebidas sobre as terras procuradas. No caso específico do descobrimento das Américas, a referência anterior que ajudou a forjar o imaginário europeu sobre a região eram as Índias Orientais, cujos relatos remetem ao período da Antiguidade. Sendo assim, o europeu colonizador trouxe referências simbólicas constituídas sobre a região na sua chegada ao chamado Novo Mundo. Segundo Gondim (1994, p. 16):

Essas histórias maravilhosas falavam de povos estranhos, grotescos, monstruosos. A natureza não menos fantástica era povoada por animais não menos estranhos: unicórnios passeavam por entre vegetações encantadas, composta por ervas capazes de curar qualquer doença, podendo ser encontradas próximas à fonte da juventude. Eram histórias construídas, coletadas ou reproduzidas a partir de relatos de homens que viveram na Antiguidade, como Heródoto, almirantes que comandaram a expedição de 
reconhecimento do Rio Indo a mando de Alexandre, o Grande, padres missionários que visitaram o reino do Grão Khan, peregrinos em busca de lugares santos, comerciantes árabes e judeus. Muitos viajavam à procura do berço da humanidade descrito na Sagrada Escritura ou em busca da história de sua raça.

Para Beluzzo (1996, p. 4), o legado iconográfico e a literatura de viagem dos cronistas europeus trazem sempre a possibilidade de novas aproximações com a história do Brasil. No entanto, essas obras só podem dar a ver um Brasil pensado por outros. Deslocar os conceitos e imagens forjados nos relatos dos viajantes e descobridores europeus acerca do chamado Novo Mundo para uma nova perspectiva de análise, buscando identificar nesses discursos matrizes dos modos de representação da Amazônia constitui fator importante para a análise da representação da região concretizada nos discursos materializados em diferentes esferas do conhecimento, da ciência à arte.

A chegada ao continente americano amplia as concepções do europeu em relação ao que poderiam encontrar nas terras dos outros continentes. Em busca de matérias-primas e riquezas naturais, os europeus se deparam com uma natureza exuberante, que oferece uma gama muito ampliada de possibilidades a serem exploradas, de modo que a atenção aos povos habitantes dessas terras seria o de uma aproximação interessada apenas na facilitação do acesso às potenciais riquezas naturais, aos meios necessários para sua exploração e aos conhecimentos tradicionais, daí a região ser tomada como campo privilegiado de pesquisas científicas, um verdadeiro paraíso para os naturalistas, como comprovam as coleções etnográficas reunidas pelas expedições que passaram pela Amazônia.

Os relatos dos cronistas europeus tomam contornos fantásticos nesse encontro entre duas sociedades absolutamente distintas. São temporalidades e matrizes de pensamento muito diferentes entre si. O europeu não estava interessado na cultura originária dos habitantes da América, ao menos não em entendê-la ou preservá-la, por isso projetava sobre os povos americanos imagens e alegorias fantasiosas, ignorando sua especificidade e sua realidade, descrevendo figuras bestiais e mitológicas como originárias desse "Novo Mundo". 
Segundo Sevcenko (1996, p. 110) é possível

Dentro do processo de colonização, avaliar duas formas de percepção mais ou menos peculiares dos europeus, que não são em princípio dissociadas entre si, mas que acabam se tornando atitudes especializadas no contexto da evolução do processo colonizador: a primeira é o impulso desejante [...] essa espécie de sentimento [...] que é o desejo pelo desconhecido, a vontade de conquistar, penetrar naquilo que é virgem e indevassável, intocado. $[\ldots]$

A outra forma de percepção europeia é a prática propriamente agressiva do ato ou da intervenção colonizadora, e que implica no contato direto, físico, com esse meio - em função da extração daquilo que se veio buscar pelo ato da colonização: o vegetal tropical ou o minério.

Esse impulso desejante mostra-nos a matriz de algumas idealizações relativas à Amazônia no imaginário europeu do século XVI, com a referência ao ato sensual da conquista e da penetração numa terra fértil no primeiro caso e a concretização da pretensa superioridade européia através do empreendimento hostil e bélico da investida colonial no segundo.

Theodoro (1996, p. 77) vai além e questiona "Por que a narrativa do século XVI é sempre parte de um sonho?", onde se podia identificar diversas figuras fantásticas e mitológicas, no que a própria autora responde que os sonhos do século XV I estavam ligados ao movimento, à fuga, já que o cotidiano transcorria de forma profundamente estática e opressiva. De certa forma, imaginar também era viajar.

A disparidade nessas percepções sobre a colonização do chamado Novo Mundo, nos faz atentar ao fato de que o encontro entre culturas, resultado das viagens para o além-mar, resultou em processos contraditórios, fundamentos dos diferentes discursos que se consolidariam sobre a região.

Talvez a vertente mais forte dos relatos sobre o chamado Novo Mundo seja a do discurso dos viajantes, que se estenderá durante os séculos sendo reproduzida, modificada ou atualizada com o passar do tempo, estando presente ainda hoje nas diversas narrativas que se ocupam da região amazônica. No discurso dos viajantes encontramos referências recorrentes a 
inúmeras situações generalizantes sobre a Amazônia, resultado de um olhar eurocêntrico fascinado, onde não faltam referências à exuberância da natureza e a sua incrível biodiversidade, discurso este profundamente marcado pelas ciências naturais, uma vez que foram predominantemente naturalistas os viajantes que passaram pela Amazônia, local onde encontraram campo fértil para catalogações e coletas. Para Souza (2003, p. 59)

Foram esses relatos que serviram, posteriormente, em grande parte, na orientação, classificação e interpretação da região como literatura e ciência; foram eles, perscrutadores do fantástico e do maravilhoso, que permitiram o conhecimento das coisas visíveis e invisíveis, guiando uma futura expressão de representar o enigma regional numa peculiar escritura. A Amazônia abria-se aos olhos do Ocidente com seus rios enormes como dantes nunca vistos e a selva, pela primeira vez, deixando-se envolver. Uma visão de deslumbrados que não esperavam conhecer tantas novidades.

\section{Sobre a questão do exotismo}

Para Corrêa da Silva (2001, p. 118), o processo de intervenção européia sobre os territórios e povos do Novo Mundo constitui-se no evento da mais alta importância dos contatos entre povos já realizados. Com a descoberta das Américas o europeu descobre uma alteridade que colocava num outro nível sua própria concepção de humanidade. Gondim (1994, p. 16) vai além e coloca que a existência do antimundo revelada pelas viagens ultramarinas destacou a ignorância em que estivera mergulbado durante séculos o conhecimento do homem. Para Beluzzo (1996, p. 4):

$\mathrm{Na}$ origem, as imagens elaboradas pelos viajantes participam da construção da identidade europeia. Apontam modos como as culturas se olham e olham as outras, como estabelecem igualdades e desigualdades, como imaginam semelhanças e diferenças, como conformam o mesmo e o outro.

Para pensar o encontro dos europeus conquistadores com os povos das terras recém-descobertas, Carvalho (2002, p. 122) vai buscar em Tzvetan 
Todorov os "princípios fundadores da alteridade", que serviriam de chave para uma definição da ideia de estrangeiro. São a Regra de Homero e a Regra de Heródoto, nos interessa aqui a ideia da segunda, que segundo Carvalho (2002, p. 122) é a regra "para a qual determinadas sociedades, baseadas em supostas supremacias econômico-culturais, considerar-se-iam as melhores do mundo, passando, a partir desse critério valorativo, a julgar as outras como inferiores, pérfidas, incapazes, não-racionais." Sendo assim, funda-se também nesse momento uma visão que insinua a inferioridade do homem das Américas, particularmente daquele que vive abaixo da linha do Equador, frente ao europeu, concepção que tem como base um determinismo biológico de matriz evolucionista, para o qual seria impossível o fortalecimento de uma cultura pungente nos trópicos úmidos das Américas.

Nessa marcha para o oeste, com o avanço marítimo da civilização europeia para o chamado Novo Mundo, temos um verdadeiro massacre etnográfico, com a imposição dos valores e da cultura de uma determinada sociedade sobre os valores e a cultura de outras. Ainda segundo Carvalho (2002, p. 124):

Essas alteridades, cifradas pelo panorama da nudez, dos prazeres ansiosos, das belezas lascivas, da nãomercantilidade, acabaram por produzir uma revolução sem precedentes no imaginário ocidental, abalando o suposto reinado civilizatório e a arrogância de seus súditos e mandatários, ainda que sua historicidade fosse entendida como um discurso negativo, um somatório de ausências, que as colocava fora da própria história.

Em virtude dessa negatividade, foi difícil ao Ocidente entendê-las como manifestações culturais plenas. Talvez, por isso, tornou-se obsessiva a compulsão de domá-las, escravizá-las, contaminá-las, domesticá-las, sob a ideologização de que eram inferiores, estranhas, estrangeiras, mantendo-as no patamar de uma não cidadania cultural, sempre espúria e subalterna.

Essa noção de inferioridade está também na matriz das exotizações sobre a região enquanto lugar do fantástico e do misterioso, do intocado e do exuberante, pois essa inferioridade era reveladora de uma "não-cidadania 
cultural", conforme colocou Carvalho (2002, p.124).

Diversos são os relatos dos viajantes que passaram pela Amazônia no início do século XVI. Em comum entre eles a descrição de imagens exóticas e fantásticas sobre o chamado Novo Mundo, fato que levaria à criação de diversos mitos sobre a região. Entre histórias de feras bestiais e povos categorizados como primitivos, destaca-se a das mulheres guerreiras, imediatamente identificadas com o mito grego das Amazonas que, segundo Krüger, (1987, p. 159) “inaugura a tradição de se ver a região amazônica como um conjunto de exotismos. E mais: um conjunto de impossibilidades, onde não existe a realidade social, mas tão somente a lenda."

Assim, desde o mito inaugural do exotismo sobre a região, temos difundida a ideia de que ali não havia lugar para uma sociedade organizada, não existia cultura senão barbárie, numa visão predominantemente eurocêntrica sobre a Amazônia. Segundo Carvalho (2002, p. 123),

Toda episteme do século XVI, misto de magia e erudição, fixará o espaço do exotismo como essencial para a fundação de uma discursividade que conseguisse incorporar aos espaços "civilizados" todos os restos do mundo ainda desconhecidos, numa tentativa de assimilação compulsória, que mantinha todos esses outros como uma reserva de valor, que não havia ainda ascendido à racionalidade plena.

A categorização de exótico carrega consigo umainegável carga discursiva que revela um embate de forças entre aquele que é o objeto da categorização, julgado como exótico, pois diferente, e aquele que é o autor da categorização, detentor do discurso dominante. Como dissemos anteriormente coloca-se aqui uma relação de poder. $\mathrm{O}$ uso de categorias fantásticas para explicar a realidade encontrada nos locais recém-descobertos revela uma apreensão da região centrada em construções imaginárias apriorísticas, ignorando seu processo histórico social.

Ao nos determos particularmente na análise do pensamento social sobre a Amazônia, notaremos que essa foi uma região pensada "de fora pra dentro", ou seja, sempre foi determinada por uma produção de conhecimento 
exterior à sua realidade, uma produção que não estava comprometida em analisar os processos socioculturais da Amazônia na sua complexidade, mas sim tomá-la como objeto de estudos orientado por interesses estrangeiros e exteriores, e nessa matriz de pensamento podemos notar uma predominância das ciências naturais, o que contribuiu para que os aspectos relativos à sua natureza e biodiversidade fossem priorizados nos discursos predominantes acerca da região, evidentemente devido à real imponência da floresta amazônica, daí a referência reiterada à visão dos viajantes sobre a região, que historicamente foram sujeitos advindos de outras regiões a fim de explorar especiarias e matérias-primas passíveis de serem exploradas comercialmente a fim de gerar acúmulo de riqueza das colônias.

Tal processo de exotização, é bom que se diga, não acontece de forma inequívoca, mas num processo de diálogo entre as culturas em contato, um processo de forças desiguais é verdade, onde prevalece o discurso daquele que "descobre" em detrimento daquele que é "descoberto", sendo esta uma formulação que ainda mantém em seu cerne a força da ideia de uma afirmação etnocêntrica, que opõe em pólos opostos as culturas em contato, com posições antagônicas pré-definidas, marcando as relações de apropriação ou diferenciação cultural.

Levando adiante a questão da exotização, Pinto (2006, p. 80) tem uma formulação interessante sobre tal processo, onde considera o papel do contato entre as culturas como um momento em que estão envolvidas duas esferas, uma que cataloga e outra que é catalogada, por assim dizer, portanto um evento de troca mútua.

A exotização a que determinadas sociedades, países, regiões e grupos humanos recorrem para tratar seus próprios constituintes culturais tem sido na verdade um recurso usual acionado para processar, ao mesmo tempo, suas relações com os padrões envolventes da civilização ocidental moderna, a partir da qual se disseminam ideias como a de exótico, primitivo e selvagem, sem que tal recurso venha a representar uma ameaça aos seus modos de ser, suas raízes profundas, seus mitos e valores maiores. O que significa admitir que a exotização é via de mão dupla e que determinadas situações funcionam como 
o principal elemento de reconfiguração da identidade cultural.

Assim podemos notar como o exótico, representação que prevalece no discurso do viajante, está também presente no discurso do nativo, sendo, portanto, processo de uma construção feita a partir de aproximações, apropriações e redefinições de leituras e conceitos. Pinto vai além (2006, p. 84-85) e coloca que

nas abordagens de regiões como a Amazônia, seus povos, sua paisagem, sua geografia cultural tão complexa, é praticamente impossível escapar à exotização e o que tem acontecido é um processo de autoexotização em que se abre a possibilidade de reprocessamentos e reinvenções críticas.

Como dito anteriormente, a real exuberância da floresta se impõem ao imaginário europeu e serve de palco para a elaboração de imagens míticas e fantásticas sobre sua realidade.

\section{Sobre a questão da autoexotização}

Nesse ponto devemos indagar como o exótico está presente nas representações da Amazônia feitas, digamos, de forma endógena, ou seja, as representações que são formuladas a partir da própria região, por aqueles que nela vivem e, por oposição, como está presente nas representações exógenas, formuladas por aqueles que não vivem na região, mas sobre ela produziram. O que Pinto (2006, p. 80) sugere é que o discurso surgido em regiões como a Amazônia pode valer-se de uma maneira de se autorrepresentar que estabelece uma tensão entre a representação exógena, aquela que se origina do discurso triunfante da lógica ocidental e aquela feita pelas culturas subalternas a essa lógica, que seriam as representações endógenas, originadas da seleção de partes de sua totalidade cultural, destacando aspectos diferenciais, para fazer frente às ideias generalizantes imperantes. Com essa seleção, a representação endógena poderia fazer frente aos estereótipos e reducionismos acionados 
para a sua representação por parte do discurso dominante, deslocando a questão para a observação crítica de aspectos de sua qualidade exótica, e não para a exaltação da peculiaridade ou da excentricidade. "Essas buscas de nossas origens e raizes têm resultado em projetos polêmicos como os diversos indianismos e nativismos, mas é dai que têm surgido projetos de autonomização cultural e estética, como foi o caso do movimento antropofágico de Oswald de Andrade e do Cinema Novo de Glauber Rocha." (PINTO, 2006, p. 82). Portanto, é bom que se diga, tal processo de autoexotização deve levar em conta boa medida de criticidade acerca dos seus processos socioculturais e da sua historicidade, para assim forçar uma ruptura com o discurso dominante, e não somente incorrer em autoexotizações que exaltem o folclórico e o superficial.

Em relação à produção amazonense, buscamos trazer aqui um momento importante da sua produção cultural e artística, onde uma revisão crítica da historiografia da região tomou curso, quando um grupo de pessoas buscou refletir criticamente sobre o processo histórico do Estado, resgatando aspectos obscuros de seu passado, esquecidos e massacrados pelo discurso colonialista imperante, forjando uma nova perspectiva cultural para a região, uma perspectiva em que se valoriza o rico aspecto cultural legado pelas culturas indígenas originárias da região, assim como sua diversidade étnica e cultural. Interessa-nos aqui identificar um projeto intelectual que ousou repensar o processo histórico e cultural estadual, forjando assim uma onda de afirmação cultural, presente em diferentes manifestações artísticas, inventando outra Amazônia, diferente daquela que estava sendo, também, inventada pelo discurso oficial do período.

\section{Da produção cultural e artística do Amazonas}

Para Pinto (2006, p. 34), "em torno da Amaz̧ônia tem se produzido e se acumulado, particularmente ao longo dos três últimos séculos, um considerável acervo de pensamento sobre o homem, a sociedade e suas relações com a natureza", entretanto, continua o autor, "o conhecimento atual que dispomos sobre tais temas é ainda bastante fragmentado e incompleto". Essas constatações estão na base de suas proposições para a reconstrução da história das ideias sobre a região, identificando autores que ajudaram a consolidar o pensamento social sobre a região. Além 
de esclarecer sob que matrizes conceituais e ideológicas se forjou a ideia de Amazônia nos últimos séculos, fornecendo novas e originais bases para pesquisas no campo das ciências humanas, tal procedimento seria, segundo Pinto (2006, p. 34), "fonte de novos estímulos e mesmo de uma nova consciência para os que trabalham no terreno da criação artística."

Para Souza (2003, p.20),

O Amazonas tem sido incapaz de captar uma visão essencial do seu processo, atado ao desconhecimento do caráter social do pensamento e da cultura. É como se o fenômeno social da cultura fosse uma trivial sucessão de realizações individuais, sem consciência da historicidade do ato. Esta ideologia é típica de sociedades marginais e colonizadas.

Esse desconhecimento da sua historicidade, refletido no campo da produção cultural, seria revelador de certa (SOUZA, 2003, p. 20) "disritmia cultural e histórica" do Estado do Amazonas, cuja produção artística seria fruto de (SOUZA, 2003, p. 25) "fracasso do academicismo e da pobreza técnica" que logrou obras anêmicas, que não enxergam as contradições e tragédias do homem da Amazônia; obras que estão descompromissadas com a realidade da região, que ignoram sua complexa diversidade sociocultural, orientadas, conscientemente ou não, pela ideologia colonialista que marcou a história da região, resultando em incursões superficiais no campo da estética e das artes, figurando arremedos de uma produção cultural imposta pelo beletrismo de matriz europeia difundido pela elite regional nos tempos áureos do ciclo da borracha, em tudo distante da realidade do que podemos chamar de Amazônia profunda.

É certo que tal disritmia, como considerou Souza, não é exclusividade do Estado do Amazonas, senão condição histórica quase hegemônica da produção cultural nacional. Em um célebre ensaio intitulado As ideias fora do lugar, Schwarz (1981) analisa o processo cultural brasileiro e sua relação com as ideias do liberalismo europeu do século XIX, revelando uma submissão a essa matriz ideológica, às quais contrapõe o escravismo brasileiro como definidor de uma situação intelectual, social e ideológica das classes sociais no Brasil, que seria marcada pelo fenômeno do favor como condicionante 
na relação entre as classes, fato que distanciaria a situação brasileira do ideal iluminista europeu. Para o autor as ideias européias estavam "fora do centro" no caso brasileiro, pois (SCHWARZ, 1981, p. 16)

No processo de sua afirmação histórica, a civilização burguesa postulara a autonomia da pessoa, a universalidade da lei, a cultura desinteressada, a remuneração objetiva, a ética do trabalho, etc. - contra as prerrogativas do Ancient Régime. O favor, ponto por ponto, pratica a dependência da pessoa, a exceção à regra, a cultura interessada, remuneração e serviços pessoais.

Para o autor, tal desajuste seria uma condição inevitável, pois impetrada pela situação colonial, que permanece nas relações entre classes. Tal explicação, de fundo economicista, pois considera as relações de produção, quando levada ao campo cultural, revela uma submissão aonde (1981, p. 23)

Está-se vendo que este chão social é de consequência para a história da cultura: uma gravitação complexa, em que volta e meia se repete uma constelação na qual a ideologia hegemônica do Ocidente faz figura derrisória, de mania entre manias. O que é um modo, também, de indicar o alcance mundial que tem e podem ter as nossas esquisitices nacionais.

Com essas observações de Schwarz, podemos notar que a tendência ao folclórico e ornamental não reside apenas nas manifestações culturais e artísticas regionais, como é o caso amazonense aqui avaliado, mas antes nas manifestações nacionais, cuja sucessão de pastiches como identidade nacional revela (SCHWARZ, 1981, p. 23) "o desacordo entre a representação e o que, pensando bem, sabemos ser o seu contexto".

Sobre o campo da produção artística no Estado do Amazonas e a relação entre o conhecimento da historicidade e a produção artística e cultural, Pinto acredita que (2006, p. 34)

Talvez uma das razões para a nossa pobreza no campo da criação (literatura, artes plásticas, teatro, cinema) seja uma 
certa ausência de perspectiva histórica, de conhecimento mesmo do passado, do intrincado tecido de nossas múltiplas identidades culturais. O sintoma principal é a folclorização de muitos elementos dessas identidades, de seu tratamento banal e episódico. Os poucos artistas que conseguiram perceber essa riqueza, e por serem tão poucos e excepcionais, confirmam fortemente a regra.

Ao esboçarmos essa reflexão sobre o processo cultural regional, buscando estabeleceruma relação entre História e Cultura, estamos trabalhando com autores que se lançaram ao Pensamento Social na Amazônia muito recentemente. Para Coelho (1994, p.177), no que tange a Amazônia em particular, contudo, a relação História e Cultura não atingiu ainda o nivel da discussão teórica mais elaborada”. Para desenvolver um pouco essas ideias, cabe aqui lembrar que o processo de formação universitária no Norte do País é relativamente recente em algumas áreas do saber, sendo o conhecimento construído notoriamente de "fora pra dentro", ficando a formação de pesquisadores concentrada nas universidades, museus e institutos históricos dos grandes centros econômicos, ficando as regiões mais afastadas, especialmente a região Norte, relegadas à repetição de conhecimento produzido por outros. Tal processo apenas endossa em nível nacional o papel histórico da região como campo privilegiado de pesquisas para diversos cientistas e pesquisadores do mundo todo que desde o século XVI visitaram a região, tomando-a como objeto.

É importante aqui marcar uma distinção entre essa produção cultural que identificamos como anêmica, pois desligada dos aspectos sociais do seu contexto e marcada por certo academicismo ou beletrismo de matriz europeia, como colocado acima, para a produção artística comprometida com a criticidade e com a investigação social. Para Coutinho (2005), na criação artística deve ser imperativo o compromisso com a liberdade, que precisa ser ampla e radical, sendo necessário que o sujeito comprometa-se com (2005, p. 39) "os valores e princípios que considera os mais adequados à sua personalidade enquanto criador". Pois bem, esta parece ser a faceta mais óbvia da personalidade necessária ao trabalho criativo, como o próprio autor adverte em seu texto; entretanto, tal aspecto precisa ser colocado para o que segue na reflexão de Coutinho (2005), para quem tal liberdade está condicionada por dois "limites", que seriam: (2005, p. 39-40) 
Em primeiro lugar, operando sempre num quadro histórico-social concreto, a liberdade de criação implica condicionamentos sociais, dos quais o criador pode ou não estar consciente. E, dado que a liberdade em geral é também conhecimento da necessidade, como queriam Hegel e Engels, então a específica liberdade de criação não será restringida - mas antes potenciada - se o criador tomar consciência das implicações sociais (tanto do ponto de vista da gênese quanto dos efeitos) de sua produção cultural. [...]

Em segundo lugar, a mais ampla liberdade de criação tem como contrapartida necessária a mais ampla liberdade de crítica: se só ao criador cabe, em última instância, definir os conteúdos e as formas de sua criação (o que ele fará de modo tanto mais livre quanto for consciente dos condicionamentos sociais a que me referi), ao crítico cultural cabe o direito de exercer a sua plena liberdade de avaliar - em nome dos critérios que considerar válidos os resultados concretos dessa criação.

Uma obra importante para identificar um movimento crítico em direção ao pensamento social na Amazônia é o ensaio $A$ expressão amazonense, de autoria de Márcio Souza, obra que, segundo Pinto (2006), ao lado dos textos ficcionais $A$ resistivel ascenção do boto tucuxi e Galvez, o imperador do Acre, do mesmo autor, (PINTO, 2006, p.83) representam o mais cortante ponto de ruptura na producão intelectual do Norte, exatamente porque toma como assunto os aspectos exóticos da vida social, intelectual e politica do Norte do Brasil e faz aí uma lúcida, corajosa e necessária operação de desvendamento. Essas obras de Márcio Souza citadas por Pinto são publicadas no final da década de 1970, mais precisamente em 1976, caso de Galvez - Imperador do Acre, e 1977, caso de A expressão Amazonense. O livro A resistível ascenção do boto tucuxi seria publicado posteriormente, em 1982.

\section{Considerações finais}

Os contatos iniciais dos viajantes europeus com os povos do 
chamado Novo Mundo colocam em evidência o poder simbólico da categorização advinda desse encontro. Nesse embate de forças desiguais, o colonizador europeu marcou eternamente os povos tradicionais das terras recém descobertas sob o jugo do exotismo e do preconceito, pelos quais foi considerado inferior e, logo, submisso. Tornado objeto, o homem do chamado Novo Mundo estava marcado pelo signo do exótico.

Nessa "geografia do exótico" na qual a Amazônia está incluída, cabe não somente a pré-concepção imaginária e negativa, mas também o que podemos considerar uma autoexotização. Por sua vez, essa parece ter duas condições: primeiro pode ser fruto da mentalidade colonizada, ingênua, refletida em simulacros da representação hegemônica, reverberando as práticas colonialistas na esfera local; ou pode ser fruto das práticas críticas e reflexivas, que buscam lançar um novo olhar para o discurso oficial preponderante, reinventando sua história, em práticas artísticas e socioculturais relevantes.

\section{Referências}

BELUZZO, Ana Maria. A propósito d'o Brasil dos viajantes. Revista USP n. 30. São Paulo: Universidade de São Paulo, junho/julho/agosto de 1996. p. 8-19. CARVALHO, Edgard de Assis. Estrangeiras imagens. In: CASTRO, Gustavo de (org.). Ensaios de complexidade. Porto Alegre: Sulina, 2002.

CORREAA DA SILVA, Marilene. Mundialização da Amazônia: Processos, contrastes e expressões. In: PERUZZO, Cicília Maria Krohlling \& PINHO, José Benedito. Comunicação e Multiculturalismo. São Paulo: INTERCOM, Manaus:Universidade do Amazonas, 2001. PP 113 - 152.

COELHO, Geraldo Mártires. História e identidade cultural na Amazônia. In: D'INCAO, Maria Angela e SILVEIRA, Isolda Maciel da. (Orgs). A Amazônia e a crise da modernização. Belém: Museu Paraense Emílio Goeldi, 1994. PP. 177-184.

COUTINHO, Carlos Nelson. Cultura e Sociedade No Brasil. In: Cultura e Sociedade no Brasil: ensaios sobre ideias e formas. 3. ed. revista e ampliada. Rio de Janeiro: DP\&A, 2005.

GONDIN, Neide. A invenção da Amazônia. São Paulo: Marco Zero, 1994.

OLIVEIRA, José Aldemir de. Amąônias: Sociedades diversas e culturas 
múltiplas. In: PERUZZO, Cicília Maria Krohlling \& PINHO, José Benedito. Comunicação e Multiculturalismo. São Paulo: Intercom, Manaus: Universidade do Amazonas, 2001, p. 101-111.

PINTO, Renan Freitas. Viagem das ideias. Manaus: Editora Valer/Prefeitura de Manaus, 2006.

SANTOS, Boaventura de Souza. Parte II - a construção dos Estados pós-coloniais. In: A gramática do tempo: por uma nova cultura política. São Paulo: Cortez, 2006.

SCHWARZ, Roberto. As ideias fora do lugar. In: Ao vencedor as batatas. São Paulo: Livraria Duas Cidades, 1981.

SEVCENKO, Nicolau. O front brasileiro na guerra verde: vegetais, colonialismo e cultura. Revista USP n. 30. São Paulo: Universidade de São Paulo, junho/ julho/agosto de 1996. PP. 108-119.

SOUZA. Márcio. A expressão amazonense - do colonialismo ao neocolonialismo. 2. ed. Manaus: Editora Valer, 2003.

THEODORO, Janice. Visões e descrições da América - Alvar Nunez Cabeça de Vaca (XVI) e Hercules Florence (XIX). Revista USP n. 30. São Paulo: Universidade de São Paulo, junho/julho/agosto de 1996. PP. 74-83.

TODOROV, Tzvetan. A conquista da América - a questão do outro. São Paulo: Martins Fontes, 2002. 